\title{
FASCÍNIO DE TRABALHAR COM LIVROS
}

\section{Implantação da Editora Senac mostra-se bem-sucedida e é referência na oferta de publicação de qualidade}

Quando aceitei o desafio de implantar o projeto de uma editora de mercado dentro do Senac-SP, não tinha nenhuma experiência na edição de livros. Havia trabalhado muitos anos como jornalista, primeiro em jornais e revistas, os chamados veículos de comunicação de massa, e depois do outro lado do balcão, como assessor de imprensa. Mais tarde tive uma curta passagem pelo mercado publicitário. Por fim, todas essas experiências acabaram convergindo para uma atividade mais abrangente, aquela que se pode definir como a de um profissional de Comunicação, exercida em grandes empresas e instituições governamentais e privadas. Livros, nada. A não ser, é lógico, na condição de leitor.

Tive, portanto, de aprender rápido os macetes de um mercado que movimenta, no Brasil, cerca de 2 bilhões de dólares por ano, relativos a mais de 400 milhões de livros impressos, para aproximadamente 50 mil títulos entre novos lançamentos e reedições.

Aprendi, para começar, que fazer livro é ótimo. Nada antes me havia proporcionado tanta gratificação profissional. Mas nem tudo é, evidentemente, um mar de rosas. O que pretendo relatar aqui é alguma coisa do que tenho aprendido nestes quatro anos e meio à frente de uma editora que, modéstia à parte, já conquistou um espaço razoável no competitivo mercado brasileiro. Hoje temos um catálogo com cerca de 220 títulos e fazemos cerca de 50 novos lançamentos anuais. Segundo os padrões consagrados pelo mercado, a Editora Senac é classificada como de porte médio. E chegamos até aqui por força e graça de um conjunto de circunstâncias, dentre as quais destaco duas principais: o total apoio que a direção do Senac-SP sempre deu a este trabalho e o excepcional nível de qualidade da equipe que conseguimos reunir.

O desafio que nos foi colocado em 1995 era duplo. Por um lado, reorganizar e incrementar o trabalho que já vinha sendo desenvolvido, fazia cerca de dois anos, pela pequena equipe que, subordinada à Gerência de Comunicação do Senac-SP, atendia à

\section{O AUTOR} A. P. Quartim de Moraes Jornalista, gerente da Editora Senac-São Paulo. 
incipiente mas crescente demanda interna por livros. Principalmente por livros paradidáticos e de referência, consumidos pela clientela da enorme variedade de cursos e programas oferecidos pela instituição nas 60 unidades espalhadas por todo o Estado de São Paulo. Seria necessário também estimular o grande corpo docente e técnico que atua no SenacSP, criando e transmitindo conhecimento, a transformar esse conhecimento em livros. Sob esse aspecto, a nossa editora teria um perfil muito parecido com o das editoras universitárias.

Por outro lado, e aí me parecia residir a maior dificuldade, a idéia era partir para o mercado, conquistar leitores, disputar espaço nas gôndolas e estantes das livrarias. Criar, enfim, uma editora comercial competitiva.

Como matéria-prima, disporíamos de todos os assuntos de alguma maneira relacionados com a extensa variedade de conteúdos trabalhados pelas unidades especializadas da instituição: hotelaria e turismo; tecnologia de educação; moda, beleza e decoração; tecnologia de negócios; informática; idiomas; saúde; comunicação e artes - enfim, praticamente tudo o que diz respeito à atividade $\mathrm{e}$ ao conhecimento humanos na área de comércio e serviços. $\mathrm{E}$ isso, desde logo, definia nosso campo de ação editorial como o da não-ficção.

Aprendi que o processo de confecção de um livro, desde o momento em que surge a idéia a ser colocada no papel - ou, diria melhor, na tela - pelo autor, até o instante em que chega às mãos do leitor, pode ser dividido basicamente em três fases: prospecção $e$ desenvolvimento, produção, comercialização.

São três momentos distintos que podem eventualmente se sobrepor no tempo, mas envolvem atividades muito específicas. O processo que doravante estarei descrevendo é o adotado pela Editora Senac. É um trabalho que vem sendo aperfeiçoado ao longo dos anos, com base na nossa experiência cotidiana. Não significa que outras editoras trabalhem exatamente da mesma forma.

\section{CORRENDO ATRÁS DO PRESTÍGIO}

$\mathrm{Na}$ fase da prospecção e desenvolvimento a obra é concebida, realizada e finalmente considerada pronta para edição.

A hipótese mais comum para essa fase é a de que a concepção da obra seja de iniciativa do autor. $E$ isso pode ocorrer de duas maneiras, ambas classificáveis como de prospecção passiva:

a) o autor escreve um livro e oferece-o à editora, diretamente ou 
por intermédio de uma agência, sendo este último caso mais comum no comércio internacional de direitos autorais. É a possibilidade mais simples e também a mais freqüente. Para a editora, existe a vantagem de que não precisa investir em pesquisa e desenvolvimento do texto. Quando se trata de um texto estrangeiro, a praxe é pagar um adiantamento sobre os direitos autorais.

b) o autor procura a editora com uma idéia, um projeto que necessita de apoio financeiro para a realização de pesquisas, viagens, entrevistas, ilustração etc. E/ou até mesmo para a remuneração do tempo que ele estará dedicando a esse trabalho. $\mathrm{O}$ editor pensa sempre duas vezes, nesse caso... Porque, das duas, uma: ou assume o custo de desenvolvimento do projeto, geralmente alto, ou vai atrás de um patrocinador ou outro parceiro que ajude a arcar com as despesas.

Um caso clássico é o do livro Chatô, o Rei do Brasil, de Fernando Morais (Companhia das Letras, 1994), obra de grande fôlego cuja pesquisa e dedicação exclusiva do autor ao texto foram viabilizadas pelo apoio da Unicamp e o patrocínio do Mappin (antes que caísse nas mãos do aventureiro que o levou à falência).

Mas há uma segunda hipótese: um livro pode ser concebido também pela editora (prospecção ativa). Nesse caso, trata-se de encontrar o autor capaz de realizar a idéia.

Como é fácil perceber, a primeira fase, a que chamamos de prospecção, é fundamental para o desempenho de uma editora. Dela resultará, por exemplo, o elenco de autores, que é o patrimônio mais valioso de uma casa publicadora. $E$ também a qualidade de seu catálogo.

Nos primeiros meses de existência da Editora Senac, uma das maiores dificuldades que enfrentávamos era conquistar autores. Isso tem a ver com um aparente paradoxo: apesar de carregarmos o nome de uma instituição educacional de atuação nacional, conhecida e respeitada, para os objetivos específicos da editora a marca Senac era mais ônus do que bônus. Por uma razão simples: a marca Senac é facilmente associada à criação e difusão de conhecimento de qualidade, com foco no nível médio, no ensino profissionalizante. $\mathrm{Na}$ verdade, é uma imagem que corresponde melhor aos objetivos de origem da instituição, criada há mais de 50 anos, do que à realidade de hoje do Senac, pelo menos no Estado de São Paulo. Recentemente, sem ter renunciado à vocação 
original, que é cumprida em padrões de excelência até para parâmetros internacionais, o Senac paulista ingressa firmemente no ensino de terceiro grau, com sete faculdades já instaladas e outras tantas a caminho.

Assim, a instituição está se transformando rapidamente numa importante universidade. Mas a imagem pública que ainda prevalece é a de uma organização educacional profissionalizante, de nível médio. E o melhor que se poderia esperar da editora de uma instituição como esta é que viesse a produzir apenas livros técnicos do mesmo nível, ainda que muito qualificados. Sentimos isso claramente, nos primórdios da editora. Ninguém voltado para o mercado encarava com entusiasmo a perspectiva de vir a trabalhar com o que parecia ser uma casa publicadora de... livrinhos técnicos! Muito menos as livrarias.

Tivemos de desenvolver uma estratégia destinada a sinalizar para o mercado que estávamos chegando com a intenção de ser uma editora também comercial, com uma linha não-ficcional muito definida. $\mathrm{E}$ isso foi feito com base em algumas ousadias, como a de lançar um livro de memórias de Plínio Marcos. "Afinal, para que a Editora Senac está publicando um autor maldito como esse?", perguntavam-me. "Exatamente para você me fazer essa pergunta”, eu respondia.

Voltando então ao ponto da importância da primeira fase, a da prospecção, no propósito de criar para a Editora Senac a imagem de casa publicadora comercial de livros de interesse geral, foi necessário escolher cuidadosamente uma certa quantidade de títulos especialmente com o intuito de atingir públicos específicos, importantes como formadores de opinião, e de assim angariar prestígio para o nosso empreendimento. Muitas vezes pensávamos mais no prestígio do que nas vendas. Tudo para fugir do estigma de editora de publicações técnicas/profissionalizantes. Não que não seja possível haver - até porque existem - grandes e importantes editoras com esse perfil. A questão é que não eram esses o perfil e o nicho de mercado que estávamos tentando conquistar.

\section{SUCESSO DE UMA ESTRATÉGIA}

Acho que foi uma boa estratégia, e os resultados o confirmam. Mas, felizmente, não posso dizer quanto tempo essa estra- 
tégia efetivamente demanda para produzir resultados, porque acabamos chegando onde queríamos por um confortável atalho. E esse atalho se chama Chic-Um guia básico de moda e estilo, de Glória Kalil.

O case de Chic - o maior best-seller da Editora Senac, com mais de 100 mil livros vendidos em três anos - ajuda a ilustrar a importância do que estamos chamando de trabalho de prospecção.

Glória Kalil, socialite conhecida e respeitada como influente jornalista especializada em moda e antiga proprietária da griffe Fiorucci no Brasil, era consultora de moda da unidade especializada do Senac paulista, o Centro de Educação em Moda - CEM. A então gerente dessa unidade lhe encomendara o roteiro de um vídeo sobre moda e estilo. Desde a criação da editora, vídeos reproduzidos em série para fins comerciais eram considerados produto editorial. Por essa razão, o competentíssimo roteiro da Glorinha veio parar em minhas mãos. Verifiquei logo que se tratava de uma produção caríssima, só viabilizável com a captação de recursos de patrocínio. Mas percebi também que ali estava o esboço de um livro interessante.

Propus o livro e a Glorinha topou o desafio sem nenhuma hesitação. Solicitou os recursos materiais e humanos que julgou necessários, obteve-os e em menos de oito meses a obra estava pronta. Lançada em 12 de dezembro de 1996, logo nos três primeiros meses vendeu cerca de 30 mil exemplares.

Quando, linhas acima, me referi a atalho, quis significar que o advento de Chic foi fundamental para a Editora Senac. Costumo dizer que, tal qual a História da Humanidade, a nossa história se divide em a. C. e d. C. - antes e depois de Chic.

Para ilustrar a importância desse lançamento, basta dizer que, quando o livro começou a ser vendido, nosso departamento comercial vinha tentando com escassos resultados, havia um ano e meio, montar uma rede de distribuidores e representantes em todo o país. Três meses depois, uma competente rede estava armada, porque aí as coisas se inverteram e nós é que passamos a ser procurados.

Esse grande êxito se confirmou um ano e meio depois com o lançamento de Chic homem, que até agora vendeu cerca de $50 \mathrm{mil}, 10$ mil dos quais no pré-lançamento feito na Bienal do Livro de 1998, dois meses antes de estar disponível no mercado.

O caso de Chic, ademais, é sui generis. É fruto de uma prospecção passiva, na medida em que a idéia original nos foi trazida, mas o produto final resultou de uma atitude ativa da editora em sua formulação e desenvolvimento. Essa postura é indispensável para a vitalidade de um catálogo editorial. 
Minha experiência revela que os títulos que resultam do trabalho de prospecção ativa são esmagadora minoria (talvez dois ou três, em cada dez), mas quase sempre proporcionam, sob todos os aspectos, um desempenho muito satisfatório. E a razão de se fazerem poucos títulos concebidos pela própria editora é simples: seu custo é geralmente muito maior, já que envolve, necessariamente, o trabalho de pesquisar e escrever.

\section{QUALIDADE DO CATÁLOGO DE TÍTULOS}

No ano passado, o jornalista Lourenço Dantas Mota, nosso consultor editorial, propôs uma idéia interessante: há um certo número de obras não-ficcionais clássicas que são fundamentais para o entendimento daquilo que se poderia chamar de "pensamento brasileiro". São títulos como Os sertões, de Euclides da Cunha, Casa grande \& senzala, de Gilberto Freire, Formação econômica do Brasil, de Celso Furtado, ou Raízes do Brasil, de Sérgio Buarque de Holanda - só para citar uns poucos mais óbvios. Ocorre que a grande maioria das pessoas, mesmo as supostamente letradas, jamais leu muitos desses títulos. Que tal, então, selecionar umas 20 dessas obras e solicitar a especialistas que façam uma competente resenha de cada uma para serem publicadas num único volume? Assim surgiu Introdução ao Brasil - Um banquete no trópico, um dos nossos mais recentes sucessos. E também um de nossos livros mais caros: só os cachês pagos a 19 resenhadores...

Não é, ainda, o forte da Editora Senac, mas a prospecção ativa se direciona também para obras prontas, geralmente até já editadas. Isso é muito comum, principalmente no que se refere às obras de ficção: romances, novelas, contos. É o mercado internacional. As grandes feiras de livros de Frankfurt, na Alemanha, de Bolonha, na Itália e de Chicago, nos Estados Unidos, servem exatamente para isso: a negociação de direitos autorais.

É necessário, portanto, estabelecer um certo equilíbrio na composição do catálogo, de modo a atender não apenas - como é óbvio - a todas as linhas que compõem o mix de produtos de uma editora, mas também à indispensável racionalização dos custos de desenvolvimento desses produtos.

A prospecção passiva pode trazer vantagens de custo, mas, se levada à condição de prática exclusiva, acabará certamente comprometendo a qualidade do catálogo. É aconselhável não apenas investir tanto quanto possível no desenvolvimento de projetos editoriais próprios, mas também criar mecanismos rigorosos de avaliação de originais e projetos oferecidos.

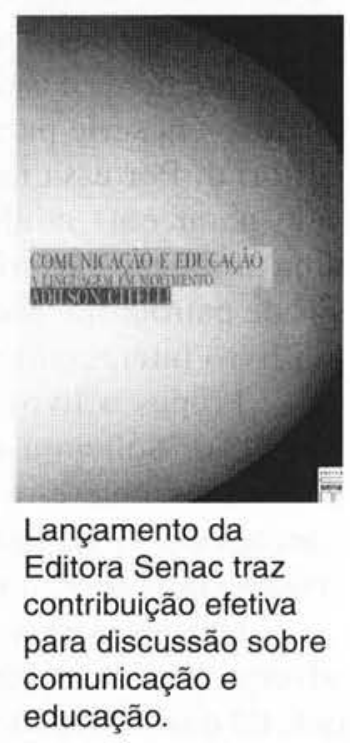

Lançamento da

Editora Senac traz contribuição efetiva para discussão sobre educação. 


\section{COMO NASCE UM LIVRO}

Bem, o autor terminou de escrever e rever seu texto e o entregou à editora. É hora de começar o processo de produção do livro, certo? Errado. O texto ainda precisa ser preparado: vai para as mãos de um profissional, um preparador, que vai ler tudo cuidadosamente, corrigir desde logo as falhas de qualquer natureza que tenham escapado ao crivo do autor e, principalmente, apontar todas as alterações que julgar necessárias ou convenientes para o melhor entendimento do texto. Esses apontamentos são submetidos ao autor, que decide se aceita ou não as sugestões. Geralmente, aceita.

O preparador fica atento também ao cumprimento das convenções gráficas adotadas pela editora. São milhares de regras que disciplinam, por exemplo, a grafia de nomes próprios, o uso de maiúsculas, das abreviações, das notas de rodapé etc.

Não se deve confundir o trabalho de preparação com o de revisão. A revisão já faz parte da fase de produção, por isso será comentada adiante.

Enquanto o texto está sendo preparado, o autor tem toda a liberdade de alterá-lo. Mas a partir do instante em que é concluído o trabalho de preparação e são incorporadas as modificações acertadas entre o preparador e o autor, este se compromete a não mais alterar o que está escrito. Porque então começa a fase de produção do livro.

É interessante observar o comportamento dos autores na fase final de desenvolvimento da obra. Alguns, geralmente aqueles que tomam contato pela primeira vez com esse procedimento, não conseguem disfarçar a contrariedade quando são informados de que um preparador vai trabalhar em cima do texto. Há os que chegam a ficar genuinamente ofendidos... Mas depois se convencem de que a preparação só faz melhorar a obra. Para outros, seu próprio trabalho nunca está suficientemente bom. Enquanto podem, mexem. A esses é necessário convencer de que, desde que os livros são escritos, um autor jamais conclui uma obra; em certo momento, ele simplesmente a abandona.

Na Editora Senac, o trabalho de preparação é obrigatório e quase todo terceirizado. É feito por profissionais especializados que geralmente trabalham em casa, com prazos bem definidos.

Vale um comentário para concluir o capítulo sobre prospeção. Entendo que o lance editorial mais brilhante de 1999 no Brasil - que envol- 
veu, portanto, um competente trabalho de prospecção, embora eu não tenha conhecimento de detalhes - foi o lançamento da Coleção Terra Brasilis, de autoria do jornalista Eduardo Bueno, o Peninha (Editora Objetiva). Composta, pelo menos até agora, de três volumes $-A$ viagem do descobrimento, Náufragos, traficantes e degredados e Capitães do Brasil - essa coleção é uma obra-prima de concepção e execução editorial: tema atualíssimo; pesquisa bem cuidada; texto absolutamente simples, saboroso e elegante; revisão caprichada; projeto gráfico original e adequado a um custo relativamente baixo, com ilustrações corretas e bastantes, o mesmo valendo para os boxes com uma grande quantidade de informações marginais pertinentes e interessantes (é um recurso de valor estimável para tornar a leitura mais amena a agradável). E, last but not least ${ }^{1}$, preço bom. Não é de causar surpresa, assim, que freqüentemente os três títulos da coleção - todos os três sejam encontrados numa mesma lista de 10 livros mais vendidos.

\section{VÁRIAS FASES DA PRODUÇÃO}

Os originais devidamente preparados, dados como definitivos, começam a se transformar em livro. São encaminhados ao profissional - ou a uma equipe, um birô - que vai desenvolver o projeto gráfico, ou seja, que vai dar forma ao livro. É nesse instante que se define o formato da obra, o que implica uma série de especificações técnicas: tiragem, medidas, diagramação do miolo (com ou sem ilustrações), tipo de capa (brochura, capa dura ou capa flexível), tipo de papel do miolo, detalhes de acabamento etc.

Definido o projeto gráfico, o texto é composto de acordo com as especificações dadas. E sai então a primeira prova, que é encaminhada para revisão. Esse trabalho é geralmente feito por uma dupla: um profissional lê a prova em voz alta e outro acompanha o texto pelo original. Pode ser feita também a chamada leitura silenciosa, em que apenas um revisor trabalha em cima do texto composto.

É na hora da revisão que um bom trabalho anterior de preparação se evidencia. Quanto melhor a preparação, tanto menos trabalhosa a revisão. A maior parte das correções que restam para fazer são de erros de digitação e de detalhes de composição gráfica, tais como espaçamento das palavras, entrelinhamento, alinhamento etc.

A primeira prova é indispensável. O ideal é que a segunda seja a última. A terceira é tolerável. A quarta já é incompetência.

Se o trabalho de preparação não é feito - e, infelizmente, isso é comum por aí, por uma questão de redução de custos -, todas as falhas do original do autor vão ser detectadas, pelo menos é o que se espera, na 
primeira prova. Quer dizer: a primeira prova sairá da revisão tão mexida, ou suja, que aumentará substancialmente a possibilidade de que a segunda prova venha ainda com muitos erros. O que torna inevitável a terceira e, quem sabe, a quarta... E essa brincadeira custa tempo e dinheiro.

Se nosso trabalho de preparação é terceirizado, o de revisão é feito por profissionais do quadro da editora. Decidimos que seria assim porque entendemos que a revisão é, na verdade, o controle de qualidade de nossos produtos. Deve, portanto, ser feito dentro de casa.

A Lei de Murphy - aquela que estabelece que, se alguma coisa pode dar errado, certamente dará - funciona inapelavelmente na produção editorial. Portanto, é inútil imaginar que um livro possa sair absolutamente perfeito, sem nenhum erro de revisão. Isso é impossível, podem crer. Mas daí à absurda quantidade de erros que é comum encontrar em muitas obras que estão pelas livrarias vai uma enorme diferença.

Tudo bem que a racionalização de custos se imponha, pois o livro já é um produto naturalmente caro no Brasil. Mas a negligência com que muitos livros são tratados em nome da redução de custos chega a ser desrespeitosa para com o leitor.

Na Editora Senac, o esmero do trabalho de preparação e revisão é ponto de honra e diferencial mercadológico. Há outras editoras que fazem esse trabalho tão bem quanto nós. Melhor, não conheço.

E a capa do livro? Esse é um assunto muito importante. Livros
A qualidade editorial é uma filosofia que se mantém ao longo de todo o processo - da produção à comercialização. não são exatamente como as publicações periódicas jornais e revistas -, cuja capa freqüentemente é fator decisivo para a compra por parte do leitor. Não conheço nenhuma pesquisa sobre o tema, mas tenho certeza de que a maior parte dos leitores, quando entra numa livraria ou faz uma encomenda por qualquer meio eletrônico, está dando curso a uma decisão de compra amadurecida e não a um impulso. No mínimo, o que ocorre é o se-

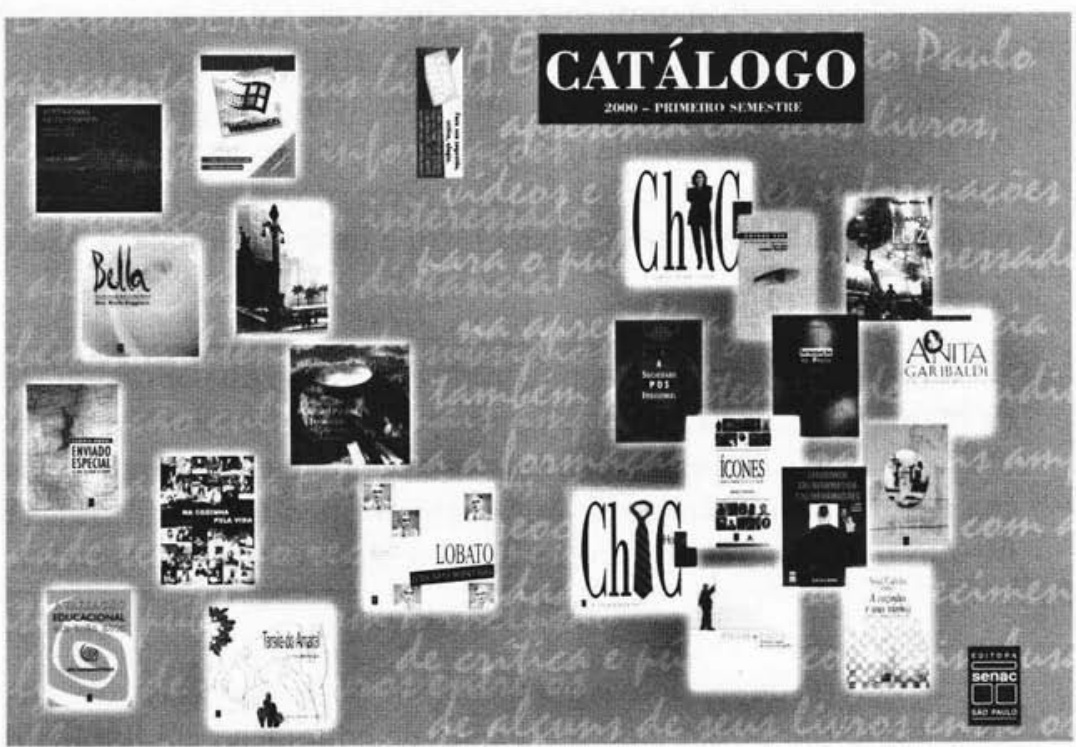


guinte: nem sempre você entra numa livraria ou consulta um catálogo na Internet sabendo exatamente o título que quer comprar; mas você sabe sempre exatamente o tipo de livro que compraria ou não.

De qualquer modo, coerente com o fundamento mercadológico de que uma boa embalagem ajuda a vender o produto, uma boa capa é sempre desejável. Mas o que é uma boa capa? Para além de toda a subjetividade que questões de gosto envolvem, entendo como boa capa a que consegue reunir duas virtudes principais. Primeiro, perfeita adequação da forma, da imagem, do conjunto de elementos visuais que a compõem ao projeto gráfico do miolo e ao conteúdo da obra. Por essa razão óbvia é que as biografias geralmente trazem na capa a figura do biografado, que os romances estampam uma imagem alusiva à história que está sendo contada ou que os textos ensaísticos sugerem capas mais despojadas, austeras. Segundo, a visibilidade a partir da vitrina, da gôndola ou da estante da livraria. Há capas que criam impacto visual, chamam o leitor de longe, destacam-se entre dezenas de outras obras com as quais dividem espaço. Em resumo: tornam fácil achar o livro que você está procurando ou despertam sua atenção para a obra que você ainda não sabe que existe.

A capa pode ser feita pelo mesmo profissional ou equipe que desenvolve o projeto gráfico do miolo, ou ser encomendada a um artista específico, um capista. Na Editora Senac, os títulos mais importantes têm capa invariavelmente encomendada a um capista do primeiro time. Essa é atividade na qual, aliás, o mercado editorial brasileiro está muito bem servido.

Definida a capa e revisado o miolo, o livro está pronto para ingressar, ainda na fase de produção, naquilo que se pode chamar de etapa industrial. Primeiro, faz-se o filme que vai queimar a chapa a partir da qual será feita a impressão. Há novas tecnologias em desenvolvimento, mas por enquanto são basicamente dois os processos: o tradicional fotolito, ainda indispensável quando se trata de imprimir imagens em cores ou meios-tons de preto, e o laser film, bem mais barato, mas adequado apenas para texto e imagens simples, a traço.

Na fase de produção, o segredo está em se dispor de um elenco de fornecedores competentes e, sobretudo, confiáveis. Pode parecer óbvio, mas a experiência demonstra que uma sólida confiança mútua é capaz de eliminar a maior parte dos pequenos e grandes problemas que geralmente infernizam a relação cliente-fornecedor.

A oferta de serviços é grande, desde birôs que desenvolvem projetos gráficos e fazem todo o trabalho de editoração até fotoliteiras e 
gráficas de todos os tipos e tamanhos. Os preços também variam, em proporções freqüentemente assustadoras...

Há grandes e excelentes gráficas que imprimem de tudo e outras que só trabalham com livros. Nossa experiência demonstra que, para atender a uma editora, as últimas são recomendáveis. Nessas, os preços costumam ser mais razoáveis e os prazos mais cońfiáveis.

\section{MERCADO PEQUENO, LIVRO CARO}

Há autores que não se conformam: "Um amigo meu procurou o livro em Florianópolis e não encontrou. Vocês não mandaram para lá?". "Passei na livraria do aeroporto e não vi o livro. Disseram-me que acabou, já pediram mais, mas ainda não receberam!". "Naquela livraria do shopping tinha o livro. Mas estava praticamente escondido. Não tinha nenhum na vitrina!"

É a hora em que o editor começa a pagar todos os seus pecados! $\mathrm{O}$ livro está impresso. Começa a última fase do processo, a comercialização. Se tudo der certo, logo tudo estará recomeçando, de forma simplificada e muito mais rápida, com as reedições. Amém!

O mercado editorial brasileiro lançou 50 mil títulos em 1998. Descontadas as reedições e os novos lançamentos de consumo compulsório, como os didáticos e paradidáticos, temos alguma coisa como 10 mil títulos novos lançados por ano. Ou mais de 25 títulos por dia! Para o tamanho de nosso mercado, não há livraria que consiga absorver totalmente essa quantidade de lançamentos, até porque nem todas se interessam por todos os tipos de livro. Da mesma forma, é impossível imaginar que haja espaço na mídia para a divulgação de todas as novidades.

Esses números dão uma boa idéia do que seja o problema da chamada distribuição de livros. Não é à toa que os autores reclamam!

Tratamos aqui de livros destinados ao público em geral, o que abrange um grande número de categorias específicas. A Câmara Brasileira do Livro - CBL - adota uma classificação temática dividida em 150 itens. Estamos falando aqui, por exemplo, de ficção, interesse geral, esotéricos, auto-ajuda, administração e negócios, infantil etc. Livros, enfim, que são comercializados pelo meio convencional que são as livrarias.

Para que um desses livros lançados no mercado chegue às livrarias, é necessário que, em primeiro lugar, esteja respaldado por um eficiente esquema de divulgação, para que o livreiro saiba de sua existência; em segundo lugar, que disponha de uma igualmente eficiente distribuição, para que possa chegar fisicamente a todos os pontos; e, finalmente, é preciso que o livreiro queira ter o livro em sua loja. 
A expressão distribuição trabalha contra os editores, porque induz as pessoas - os autores, especialmente - a acreditar que se trata pura e simplesmente de distribuir o livro pelos pontos de venda. Se ele não é encontrado em algum é porque não foi eficientemente distribuído pela editora. A verdade, óbvia, é a seguinte: quando um livro adequadamente divulgado não é encontrado numa livraria, só pode ser por três razões: está fora de catálogo; esgotou-se ali e ainda não foi reposto, ou, o que é geralmente mais provável, o livreiro simplesmente não comprou o livro, por qualquer razão que seja. De modo que quem estiver preocupado em apontar culpados pelo fato de um livro não ser encontrado numa livraria, pode colocar o editor no último lugar da fila de suspeitos.

Uma divulgação competente, indispensável para que o mercado saiba da existência de um produto novo, é a pedra de toque de todo o processo de comercialização. $O$ tipo de divulgação a ser feita depende da necessária adequação dos meios ao público-alvo que se deseja atingir.

Mas alguns fundamentos são óbvios: o público-alvo indispensável em qualquer divulgação é o constituído pelos livreiros. E esse não é um trabalho muito difícil de ser feito, nem muito dispendioso, porque a briosa categoria dos livreiros não excede o número de 1.500 em todo o país, segundo a Associação Nacional dos Livreiros - ANL. Na verdade existem no Brasil bem menos do que 1.500 livrarias ativas. Talvez a metade disso. E boa parte atua também, ou principalmente, como papelaria. De modo que um mailing list atualizado e um competente folheto são suficientes para deixar todos os livreiros do país informados sobre os lançamentos. O que não dispensa, certamente, o corpo a corpo junto aos compradores das grandes redes livreiras e das livrarias avulsas mais importantes.

Outro fundamento da divulgação de livros: dada a baixa rentabilidade desse produto, a não ser em casos absolutamente excepcionais é impossível cogitar mídia paga. Comprar espaço ou tempo nos veículos de comunicação de massa, nem pensar. No máximo, pode-se sonhar com um modesto anúncio num veículo de baixa tiragem, dirigido a um público muito segmentado. A solução, portanto, é recorrer à mídia nãopaga, à chamada divulgação espontânea no espaço editorial de jornais, revistas e emissoras de rádio e televisão. E para esse trabalho o concurso do autor ou autores da obra é fundamental. Eu diria mesmo que o maior ou menor sucesso dessa divulgação está na razão direta do empenho que o autor a ela dedica. Dentre os livros de maior sucesso lan- 
çados pela Editora Senac, os que conquistaram maior espaço na mídia foram exatamente aqueles cujos autores se empenharam pessoalmente nesse trabalho, evidentemente com uma assessoria da editora por trás. Foram os casos, mais recentes, de Chic, de Glória Kalil; Monteiro Lobato - Furacão na Botocúndia, de Vladimir Sacchetta, Márcia Camargos e Carmen Lúcia de Azevedo; Anita Garibaldi, de Paulo Markun; A cozinha e seus vinhos, de Saul Galvão; Introdução ao Brasil - Um banquete no trópico, organizado por Lourenço Dantas Mota. Não por coincidência, todos esses autores - com a única exceção de uma das co-autoras de Furacão na Botocúndia - são jornalistas. Quer dizer, são pessoas que têm contatos na imprensa e credibilidade com os coleguinhas. Fica tudo muito mais fácil.

Mas é importante observar que uma boa divulgação, embora necessária, não é suficiente para o sucesso comercial de um livro. Há dolorosos exemplos a comprová-lo, em qualquer editora.

Impresso e divulgado um livro, como fazê-lo chegar a todos os ansiosos livreiros que estão desesperados para tê-lo em suas estantes? Num país de dimensões continentais como o Brasil, torna-se indispensável a presença de um intermediário: o distribuidor ou representante. As maiores redes e as mais importantes livrarias avulsas da cidade de São Paulo são atendidas diretamente pela Editora Senac. Temos uma distribuidora que trabalha com os demais compradores em todo o Estado de São Paulo e distribuidores ou representantes nos outros Estados.

A cidade de São Paulo, só ela, responde por mais de $\mathbf{5 0 \%}$ do volume total de vendas do mercado editorial brasileiro. De modo que uma editora capaz de fazer uma distribuição eficiente nesta capital já tem boa parte de seus problemas de vendas resolvidos!

Pelo menos por enquanto, a Editora Senac não tem condições de atender diretamente a toda a capital paulista. Mas cedo ou tarde isso acabará acontecendo, porque, com todo o respeito ao dedicado e muitas vezes excepcional trabalho de distribuidoras e representantes, é certo que a distribuição feita pela própria editora funciona sempre melhor. $O$ problema é que esse serviço tem um custo fixo que muitas vezes não é economicamente compensador.

Por outro lado, os descontos impostos às editoras pelas maiores redes livreiras (uma tendência que se acentuou com o advento das megalivrarias) tendem a cada vez mais diminuir o espaço para a presença de intermediários. De fato, quando se tem que deixar $50 \%$ ou $55 \%$ do preço de capa na mão dos livreiros, percebe-se que a solução é, 
cada vez mais, negociar diretamente com o comércio varejista.

Tudo isso ajuda a explicar por que, de fato, o livro ainda é um produto caro no Brasil. Mas a razão principal para os preços de capa elevados em relação ao chamado Primeiro Mundo é, certamente, o fato de sermos um país subdesenvolvido, com baixíssimos índices de leitura. Lá, o índice é de dez livros por pessoa/ano. Aqui, é de dois e meio por pessoa/ano, incluindo os didáticos, de consumo compulsório. A consequiência é que o custo unitário de nossos livros é muito alto, pois as tiragens médias no mercado brasileiro são, com boa vontade (excluindo-se os didáticos), de 2 mil ou 3 mil exemplares. Lá, esses números se multiplicam, no mínimo, por dez.

Muito bom. Mas de que serve tudo isso se num futuro ainda imprevisível, e inexorável, as novas tecnologias de comunicação tornarão o livro um objeto obsoleto?

Estamos às vésperas de ingressar no Terceiro Milênio e o livro, na forma que o conhecemos hoje, impresso, não existe há muito mais de 500 anos. Hoje, esta forma parece enfrentar a maior ameaça a sua sobrevivência: a tecnologia digital. É possível imaginar que em alguns poucos anos possamos ter na tela do computador (e até imprimir, se assim o desejarmos!) qualquer livro editado em qualquer parte do mundo. Mais do que isso, alguns livros muito em breve já estarão sendo editados e comercializados na forma de arquivos digitais. Passos nesse sentido já se ensaiam. Não sei, portanto, se o livro vai sobreviver por muito tempo na sua forma atual. Mas a tradição milenar da transmissão do conhecimento por meio de caracteres gráficos - gravados na pedra, manuscritos, impressos ou salvos num arquivo digital - acredito que só se vá extinguir junto com a humanidade. De qualquer modo, não estaremos lá para ver.

Resumo: O depoimento do jornalista e editor-chefe da Editora Senac-São Paulo, A.P. Quartim Moraes, relata o percurso de implantação do projeto de ampliação desta editora. Fala da responsabilidade do editor desde o processo de prospecção e desenvolvimento de uma obra, preparação de texto, produção do livro até as fases de divulgação, distribuição e comercialização do livro. Destaca a necessidade de conhecimento do mercado, de ousadia na escolha de projetos a serem transformados em livros, bem como do empenho pela melhor qualidade de publicação.

Palavras-chave: Editora-Senac, editor, livro, mercado editorial, leitor, mercado livreiro
Abstract: Journalist and Editora Senac-São Paulo chief editor, A. P. Quartim Moraes, reports on the course of the implementation of the project to enhance that publishing house. It talks about the editor's responsibility all the way from a literary work's prospecting and development process, through the book's production, divulging, distribution and marketing phases. It stresses the need for market knowledge, for daringness to choose products to be transformed into books and the need for greater publication quality.

Key words: Editora-Senac, editor, book, editorial market, reader, book market 